\title{
Magnetic resonance and computed tomographic imaging in the evaluation of acute neuropsychiatric disease in systemic lupus erythematosus
}

\author{
WILMER L SIBBITT Jr, ${ }^{2}$ RANDY R SIBBITT,${ }^{3}$ RICHARD H GRIFFEY, \\ CHRISTOPHER ECKEL, 1 AND ARTHUR D BANKHURST
}

From the ${ }^{1}$ Center for Noninvasive Diagnosis and the ${ }^{2}$ Department of Medicine, Division of Clinical Immunology and Rheumatic Diseases, University of New Mexico School of Medicine, Albuquerque, New Mexico, and ${ }^{3}$ Santa Fe Imaging Center, Santa Fe, New Mexico

SUMMARY Magnetic resonance (MR) imaging and computed tomography (CT) are useful for $\overrightarrow{\vec{D}}$

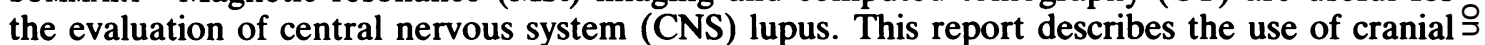
MR and CT in 21 patients with systemic lupus erythematosus (SLE) with acute neuropsychiatric $\vec{\square}$ symptoms manifested by headache, seizures, focal neurological deficits, psychosis, or organic $\mathbb{\infty}$ brain syndrome. Computed tomography was found to be insensitive and detected only diffuse $\stackrel{\mathbb{}}{乛}$ atrophy (two cases), cerebral infarct (one case), and intracerebral haemorrhage (one case) in the $\overbrace{\bar{\Phi}}$ 21 patients. Cranial MR images obtained with a General Electric 1.5 tesla Signa unit detected labile and fixed areas of increased proton intensity interpreted as focal oedema (eight cases $\$, \infty$ infarct (10 cases), haemorrhage (one), atrophy (seven), and acute sinusitis (two). Focal oedem was characterised by labile, high intensity lesions in the gray or white matter of the cerebellum, cerebrum, or brain stem, which completely resolved after aggressive corticosteroid treatment. Most high intensity reversible or fixed lesions evident on MR were not apparent on cranial CT images. In several patients sequential MR images were valuable in monitoring the efforts of treat- $\frac{\%}{D}$ ment. Although histological confirmation of the high intensity brain lesions apparent on MR is desirable, prior necropsy studies suggest that pathological confirmation may be difficult owing to the paucity of recognisable brain lesions in patients with CNS lupus. It is concluded that for the evaluation of acute neuropsychiatric SLE MR is useful and provides more information than: cranial CT.

Acute neuropsychiatric lupus is associated with headache, depression, organic brain syndrome, seizures, psychosis, paresis, and a host of other neurological and psychiatric symptoms. ${ }^{1}$ Because of the non-specific nature of these complaints, systemic lupus erythematosus (SLE) with central nervous system (CNS) symptoms presents a peculiar dilemma to the clinician. Confounding disorders, particularly bacterial meningitis, non-steroidal induced aseptic meningitis, brain abscess, steroid psychosis, and

Accepted for publication 6 April 1989.

Correspondence to $\mathrm{Dr}$ Wilmer L Sibbitt $\mathrm{Jr}$, Department of Medicine, Division of Clinical Immunology and Rheumatic Diseases, University of New Mexico School of Medicine, Albuquerque. New Mexico 87131. intracranial haemorrhage may be confused with active CNS lupus. ${ }^{1}$

The difficulty in distinguishing clinically between 을 disorders directly attributable to SLE and unrelated $\rightarrow$ neurological processes is due to the non-specific clinical signs that accompany this disease and to the $N$ absence of reliable diagnostic methods. ${ }^{1}$ Computed tomography (CT) and conventional radionuclide ? scanning are often used but are insensitive to diffuse $\underset{\omega}{ }$ lupus encephalopathy, the most common form of $q$ acute CNS lupus, even in the presence of seizures 0

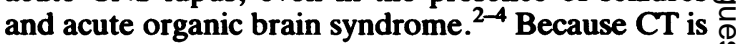
often employed before magnetic resonance (MR) in $\stackrel{\oplus}{+}$ many medical centres this study compared the sensi- 0 tivity of MR and CT in the evaluation of 21 patients with SLE with acute neuropsychiatric complaints. 


\section{Patients and methods}

\section{PATIENT POPULATION}

Patients with SLE with acute neuropsychiatric complaints were evaluated by the division of clinical immunology and rheumatic diseases at the University of New Mexico School of Medicine. The diagnosis of SLE was established using the 1982 revised American Rheumatism Association criteria. ${ }^{5}$ Table 1 lists the clinical features of the patients with SLE. Diffuse lupus encephalopathy was defined as the presence of seizures, acute organic brain syndrome, psychosis, or affective disorder, including depression that could not be ascribed to infection, drug effect, infarct, or other CNS lesion. Encephalopathy in this context is not a pathological term, but a clinical description of brain dysfunction. Other CNS disorders (infarct, haemorrhage, atrophy) were defined by characteristic MR or CT findings.

Table 1 Clinical features of the patients with systemic lupus erythematosus (SLE)

\begin{tabular}{|c|c|c|c|}
\hline $\begin{array}{l}\text { Patient } \\
\text { No }\end{array}$ & $\begin{array}{l}\text { Age } \\
\text { (years) }\end{array}$ & $\begin{array}{l}\text { Duration } \\
\text { of } S L E \\
\text { (years) }\end{array}$ & Clinical manifestations of $S L E^{*}$ \\
\hline 1 & 17 & $\mathbf{0}$ & $\begin{array}{l}\text { Rash, GN, HA, TP, lym, ser, } \\
\text { ANA, ADNA }\end{array}$ \\
\hline 2 & 36 & 7 & $\begin{array}{l}\text { GN, arth, photo, lym, vasc, rash, } \\
\text { ANA, ADNA }\end{array}$ \\
\hline 3 & 56 & 17 & TP, CNS, GN, arth, NPU, ANA \\
\hline 4 & 40 & 10 & $\begin{array}{l}\text { Rash, ser, arth, vasc, CNS, } \\
\text { ANA, ADNA }\end{array}$ \\
\hline 5 & 60 & 15 & $\begin{array}{l}\text { Rash, ser, GN, arth, CNS̃, vasc, } \\
\text { ANA, ADNA }\end{array}$ \\
\hline 6 & 17 & $<1$ & $\begin{array}{l}\text { Rash, arth, GN, CNS, leuc, } \\
\text { ANA, ADNA }\end{array}$ \\
\hline 7 & 10 & 1 & Rash, CNS, HA, GN, ANA, ADNA \\
\hline 8 & 30 & 5 & $\begin{array}{l}\text { Rash, arth, photo, GN, NPU, ANA, } \\
\text { ADNA }\end{array}$ \\
\hline 9 & 40 & 7 & Photo, ser, NPU, arth, ANA, ADNA \\
\hline 10 & 21 & 5 & Rash, ser, leuc, arth, HA, ANA \\
\hline 11 & 40 & 2 & $\begin{array}{l}\text { Rash, arth, lym, NPU, ANA, HA, } \\
\text { vasc }\end{array}$ \\
\hline 12 & 35 & $<1$ & Arth, NPU, lym, ser, vasc, CNS \\
\hline 13 & 24 & 4 & $\begin{array}{l}\text { Rash, arth, NPU, photo, ANA, vasc, } \\
\text { ADNA }\end{array}$ \\
\hline 14 & 19 & 4 & Rash, TP, ANA, ADNA, arth, photo \\
\hline 15 & 42 & 1 & Rash, arth, vasc, ANA, ADNA \\
\hline 16 & 62 & 3 & Photo, rash, arth, ANA \\
\hline 17 & 26 & 3 & Rash, arth, photo, ANA \\
\hline 18 & 34 & 7 & $\begin{array}{l}\text { Rash, arth, photo, ANA, NPU, } \\
\text { ADNA }\end{array}$ \\
\hline 19 & 52 & 1 & Rash, photo, arth, ANA. ADNA \\
\hline 20 & 26 & 4 & Rash, arth, photo, ANA, ADNA \\
\hline 21 & 24 & 3 & Rash, TP, arth, photo, ANA, ADNA \\
\hline
\end{tabular}

*ADNA=anti-DNA antibody; ANA=antinuclear antibody; arth=arthritis; $\mathbf{C N S}=$ central nervous system; $\mathbf{G N}=$ glomerulonephritis; HA=haemolytic anaemia; leuc=leucopenia; lym= lymphopenia; NPU=nasopharyngeal ulcerations; photo= photosensitivity; rash=molar rash; ser =serositis; $T$ P $=$ thrombocytopenia; vasc $=$ vasculitis.
All patients with SLE presenting with acute neurological events during a 16 month period received an admission cranial $M R$ at the center for noninvasive diagnosis at the University of New Mexico School of Medicine. Computed tomography was carried out on admission in the patient's primary hospital. Table 2 lists the 21 female patients with SLE presenting with neuropsychiatric symptoms. All MR and CT images were obtained within 24 hours of admission. If abnormalities were present on the initial MR scans sequential images were obtained at 48 hours, one week, and four weeks.

\section{MAGNETIC RESONANCE TECHNIQUE}

Magnetic resonance studies were performed on a 1.5 tesla General Electric Signa system with the 2.5 GE software. Three spin echo scans were performed on each patient: a TR $=600 \mathrm{~ms} / \mathrm{TE}=20 \mathrm{~ms}$ sagittal, a $\mathrm{TR}=200 \mathrm{~ms} / \mathrm{TE}=20 / 80 \mathrm{~ms}$ axial, and a $\mathrm{TR}=2000$ $\mathrm{ms} / \mathrm{TE}=20 / 80 \mathrm{~ms}$ coronal. Slice thickness was $5 \mathrm{~mm}$ with a $2.5 \mathrm{~mm}$ slice gap and a $256 \times 128$ acquisition matrix. The sagittal field of view was $24 \mathrm{~cm}$ with the axial and coronal images performed in a $20 \mathrm{~cm}$ field of view. Conventional cranial CT scans with contrast were performed on a GE 9800 scanner and $10 \mathrm{~mm}$ slices were taken. Two radiologists trained in MR and CT evaluated all images and reached a consensus about the final interpretation.

\section{Results}

Tables 3 and 4 summarise the MR findings.

MR FINDINGS IN DIFFUSE LUPUS

E N C E P H A L O PAT HY

The MR findings associated with diffuse encephalopathy included reversible high intensity (increased signal) lesions consistent with focal ischaemia or oedema, and fixed high intensity areas compatible with infarct evident on $\mathrm{T} 2$ weighted images (Table 4). Eight of 21 patients ( $38 \%$ ) had evidence of reversible focal lesions, and all of these patients suffered from diffuse lupus encephalopathy, though some had also shown other transient focal or generalised neurological findings. The most extensive of the reversible lesions were present in those patients with seizures, acute psychosis, severe organic brain syndrome, or focal neurological deficits, though some patients with headache also showed these lesions (Table 3). The anatomical position of these reversible, high intensity lesions was labile, and lesions resolved rapidly with corticosteroid treatment as shown by sequential images (Figs 1 and 2). None of the high intensity, reversible abnormalities was apparent by conventional CT scanning. 
1016 Sibbitt, Sibbitt, Griffey, Eckel, Bankhurst

Table 2 Patients with systemic lupus erythematosus presenting with acute neurological symptoms

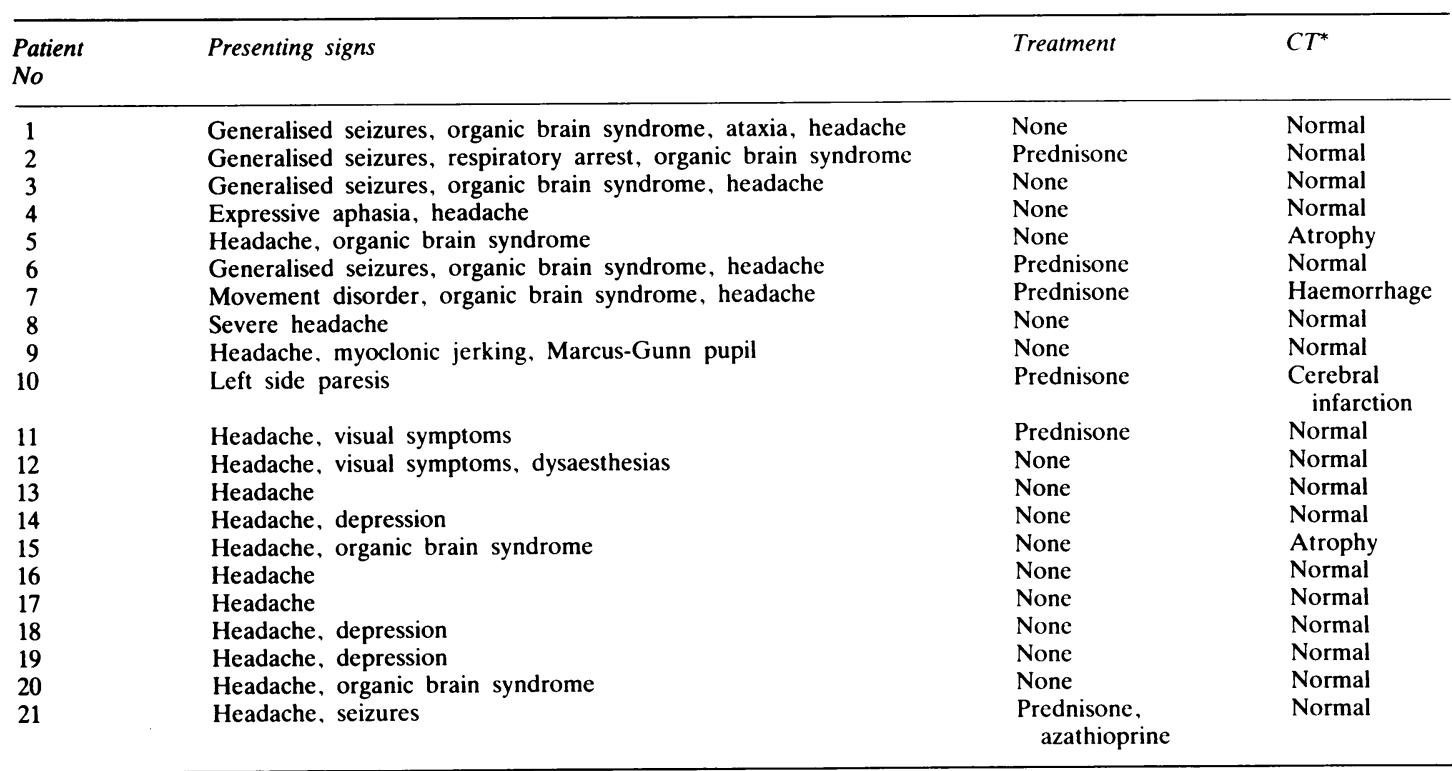

${ }^{*} \mathrm{CT}=$ computed tomography.

Table 3 Magnetic resonance (MR) findings in acute neurological lupus

\begin{tabular}{|c|c|c|c|c|c|}
\hline Patient No & Diagnosis before $M R I^{*}$ & $M R$ findings & Final diagnosis & Treatment & Response* \\
\hline 1 & Enc $v$ inf & FO, inf & Enc, inf & Prednisone & Resolution \\
\hline 2 & Enc & FO, inf, atr & Enc, inf & Prednisone & Resolution \\
\hline 3 & Enc $v$ haem & FO. inf & Enc, inf & Prednisone & Resolution \\
\hline 4 & Enc $v$ inf & Inf, atr & Enc, inf & Prednisone & Resolution \\
\hline 5 & Enc $v$ inf & Inf, atr & Enc, inf & Prednisone & Resolution \\
\hline 6 & Enc $\vee$ SPs & FO. inf & Enc, inf & Prednisone & Resolution \\
\hline 7 & Enc $v$ inf & Haem & Haem & Prednisone & Resolution \\
\hline 8 & Enc $v$ infec & Sin, atr, old, inf & Enc, inf sin & $\begin{array}{l}\text { Prednisone, } \\
\text { antibiotics }\end{array}$ & Resolution \\
\hline 9 & Enc $v$ inf & Atr. sin & Enc. sin & $\begin{array}{l}\text { Prednisone, } \\
\text { antibiotics }\end{array}$ & Resolution \\
\hline 10 & Enc $v$ inf & Inf & Vasc, enc & Prednisone & No change \\
\hline 11 & Enc $v$ infec & FO & Enc & Prednisone & Resolution \\
\hline 12 & Enc v MS & FO & Enc & Prednisone & Resolution \\
\hline 13 & Enc v psyc & Normal & Enc & Prednisone & Resolution \\
\hline 14 & Enc & FO & Enc & Prednisone & Resolution \\
\hline 15 & Enc $v$ infec & FO, inf & Enc, vasc & Prednisone & Death \\
\hline 16 & Enc & Atr & Tension headache & None & No change \\
\hline 17 & Enc & Normal & Enc & Prednisone & Resolution \\
\hline 18 & Enc & Atr & Enc & Prednisone & Resolution \\
\hline 19 & Enc & Normal & Enc & Prednisone & Resolution \\
\hline 20 & Enc & Inf & Enc. inf & Prednisone & Resolution \\
\hline 21 & Enc & Normal & Enc & Prednisone & Resolution \\
\hline
\end{tabular}

${ }^{*}$ Response refers to the resolution of symptoms and signs. not the MR findings.

atr=atrophy: enc=diffuse encephalopathy; $\mathrm{FO}=$ focal oedema characterised by high intensity lesions which completely resolve: haem = intracranial haemorrhage; inf = brain infarction characterised by high intensity MR lesions which do not resolve: infec=central nervous system infection: $M S=$ multiple sclerosis: psyc=psychiatric disorder: $\sin =$ sinusitis: $\mathbf{S P s}=$ steroid psychosis: vasc $=$ central nervous system vasculitis. 
Table 4 Magnetic resonance (MR) findings in central nervous system lupus

\begin{tabular}{|c|c|c|c|}
\hline$M R$ findings & No $(\%)$ & Interpretation & Clinical occurrence \\
\hline $\begin{array}{l}\text { Reversible punctate or focal high } \\
\text { intensity lesions }\end{array}$ & $8(38)$ & Focal oedema & Encephalopathy, focal defects, headache \\
\hline Irreversible high intensity lesions & $10(48)$ & Infarction & $\begin{array}{l}\text { Encephalopathy, CNS* vasculitis, thromboembolism, } \\
\text { longstanding SLE* }\end{array}$ \\
\hline Irreversible, sharply demarcated lesions & $1(5)$ & Haemorrhage & $\begin{array}{l}\text { CNS vasculitis, hypertension, rupture of aneurysm, } \\
\text { subarachnoid haemorrhage }\end{array}$ \\
\hline Atrophy & $7(33)$ & Atrophy & Longstanding SLE, age, recurrent infarction \\
\hline Normal & $4(19)$ & Microscopic lesions & Mild encephalopathy, small infarction \\
\hline Thickened sinus mucus membrane & $2(9)$ & Sinusitis & Active lupus, secondary infection \\
\hline
\end{tabular}

${ }^{*} \mathrm{CNS}=$ central nervous system; SLE=systemic lupus erythematosus.

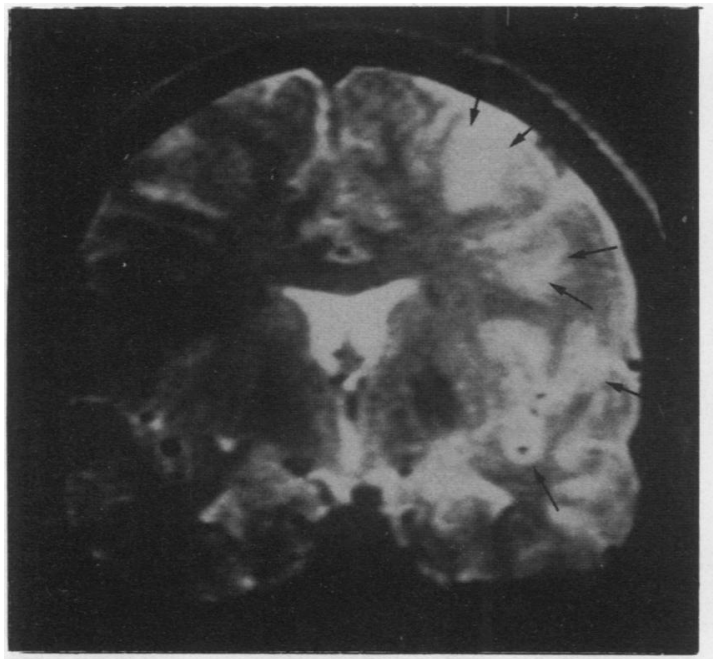

(a)

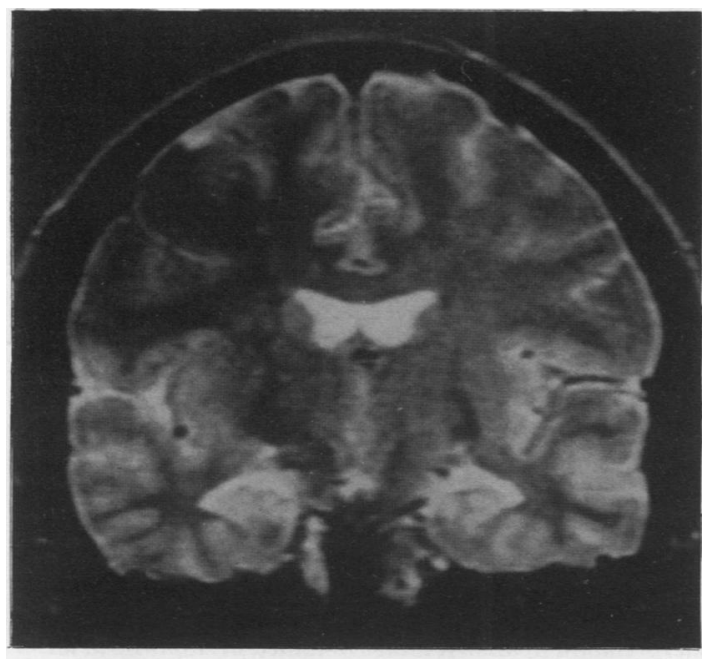

(c)

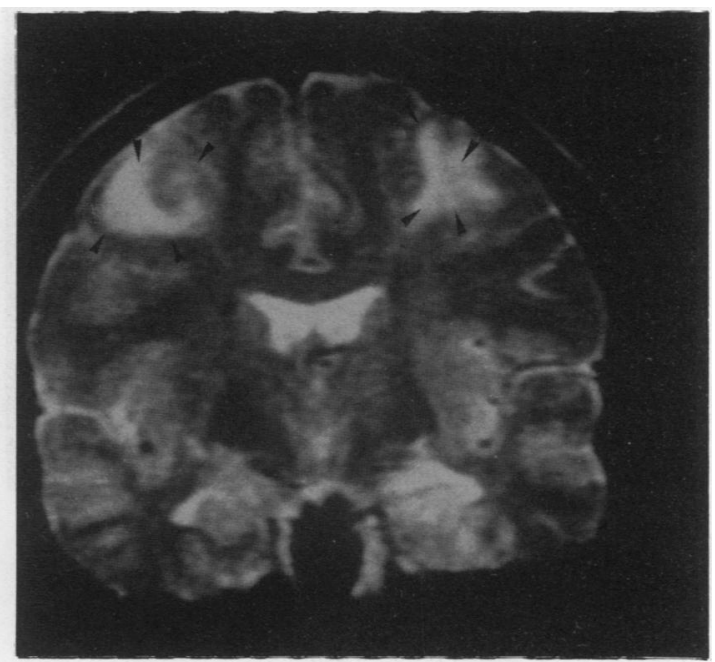

(b)

Fig. 1 Acute diffuse lupus cerebritis in the cerebrum.

Sequential $T 2$ weighted spin echo magnetic resonance $(M R)$ images $(T R=2000 \mathrm{~ms} / T E=80 \mathrm{~ms})$ on patient 1 show extensive, but entirely reversible, lesions, which represent acute lupus cerebritis without infarction (focal oedema). (a) This $M R$ study shows extensive high intensity lesions involving the cortex bilaterally and, even more prominently, the left hemisphere (arrows). The left half of the brain is brighter than the right owing to a positioning artefact due to unexpected grand mal seizures during imaging. These lesions were not present on high quality, before and after, contrast cranial computed tomography images. (b) This image represents the same patient after 72 hours of corticosteroid treatment. The abnormal areas of increased intensity have shifted in position and form (arrowheads) and have generally decreased in extent and severity. (c) After eight days of corticosteroid treatment the lesions have completely resolved and no areas of infarction are present. At four weeks the cranial MR image remained completely normal. 


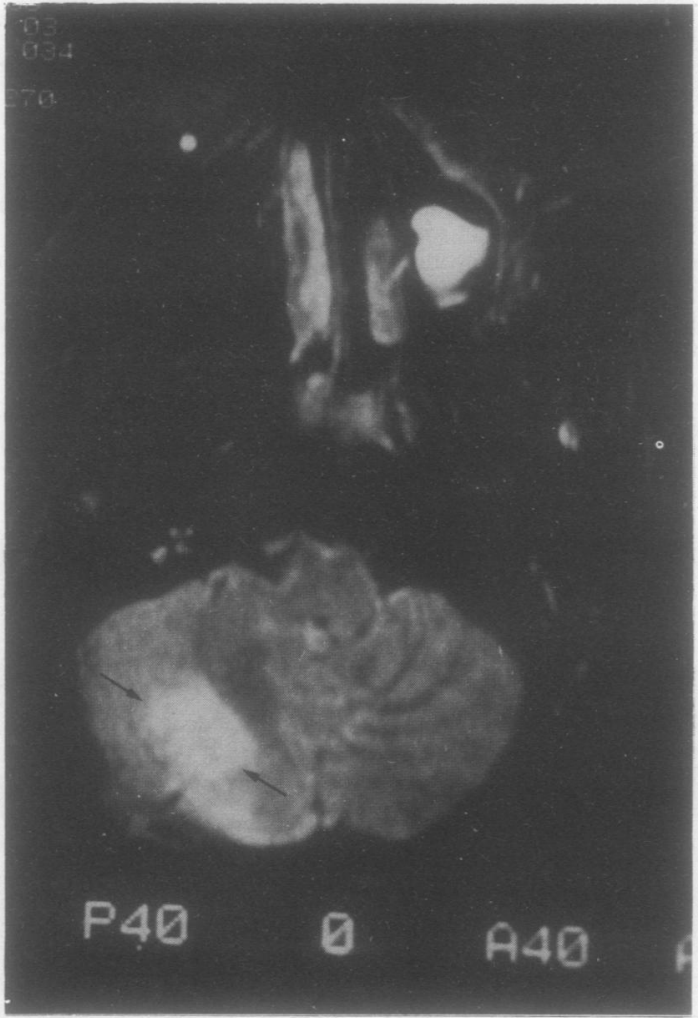

Fig. 2 Acute diffuse lupus cerebritis in the cerebellum. This magnetic resonance $(M R)$ image

$(T R=2000 \mathrm{~ms} / T E=20 \mathrm{~ms}$ ) from patient 1 shows a large reversible high intensity lesion in the cerebellum (arrows). This lesion represents focal oedema or ischaemia, not infarction, and completely resolved within eight days of corticosteroid treatment. Posterior fossa abnormalities such as these are rarely visible on computed tomography scanning. In this MR image the maxillary sinus is obscured with high intensity signal consistent with the presence of maxillary sinusitis or a retention cyst.

Fixed high intensity lesions were also apparent in many patients with diffuse encephalopathy even if reversible, labile lesions were superimposed upon this fixed pattern (Figs 3 and 4). The persistent regions of increased signal presumably represented infarction or residual tissue injury. The differentiation between the similar high intensity lesions representing reversible oedema or fixed infarction could not be determined on a single MR study but required sequential images obtained over a period of days to weeks as the patient underwent treatment. If the lesions characterised by increased proton intensity were large and diffuse (Fig. 1) they were more likely to be reversible than smaller, isolated lesions.
CEREBRAL INFARCTION ASSOCIATED WITH SLE

Infarction of brain parenchyma was a common finding in both patients with and without acute cerebritis? and was manifested by the presence of fixed, high intensity lesions. Very few of the smaller fixed $\stackrel{5}{-}$

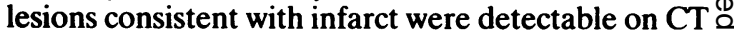
scanning. Reversible high intensity lesions were difficult to distinguish from established infarction except by sequential scanning. Infarct as defined by the presence of fixed, high intensity lesions was pre- $\vec{\omega}$ sent in 10/21 patients with acute neuropsychiatric findings. The infarct was of clinical importance only $\frac{0}{2}$ if it were large and involved important structures as in patient 10 who suffered a large right sided cerebral infarction resulting in a left sided paresis. $\vec{N}$ Figure 4a (patient 2) is a spin echo $(\mathrm{TR}=2000 \mathrm{~ms} /$

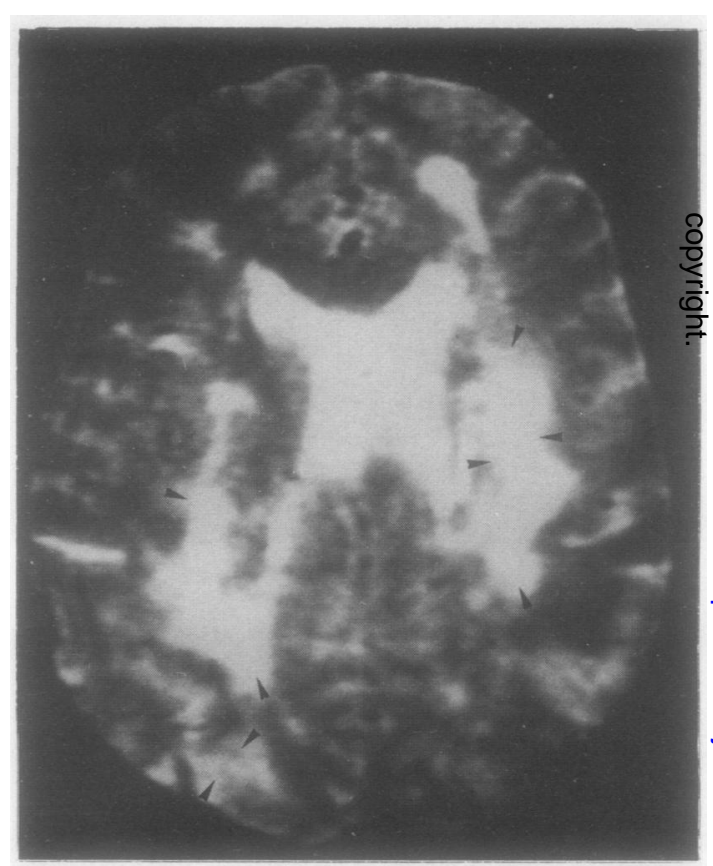

Fig. 3 Acute diffuse lupus cerebritis and chronic white matter infarction. This is a T2 weighted axial image $(T R=2000 \mathrm{~ms} / T E=20 \mathrm{~ms})$ from patient 3 . A complex combination of labile and fixed cortical and deep white matter lesions (arrowheads) is present in this study, representing oedema or ischaemia (reversible lesions) and infarction (irreversible lesions). Without a baseline magnetic resonance (MR) image. Serial scanning is the only way to differentiate between new and old lesions and reversible and irreversible lesions. Because of this an initial MR study during remission is valuable to record the baseline anatomic status of the central nervous system (CNS) in order to permit interpretation of an $M R$ image obtained in response to an acute $C N S$ event in a lupus patient. 


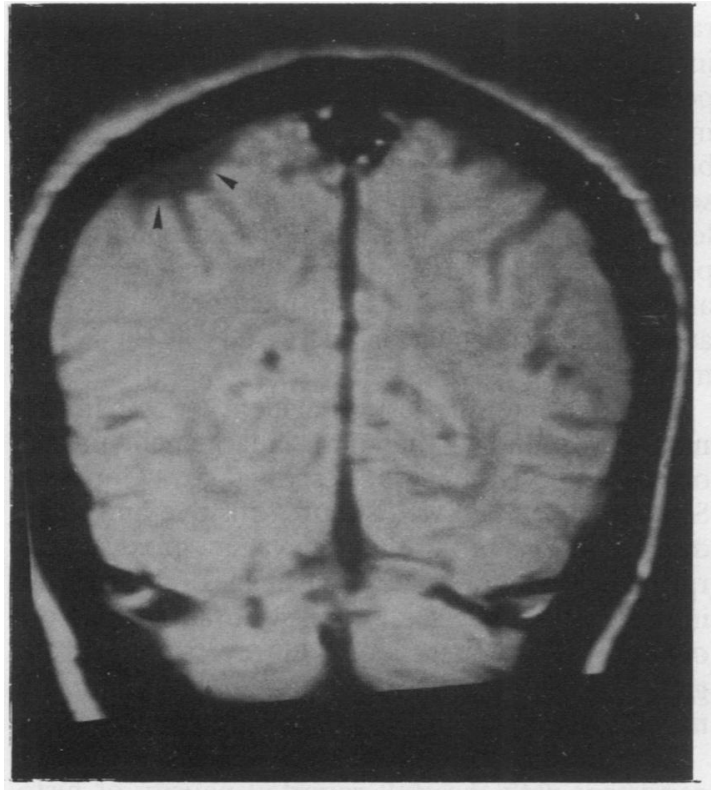

(a)

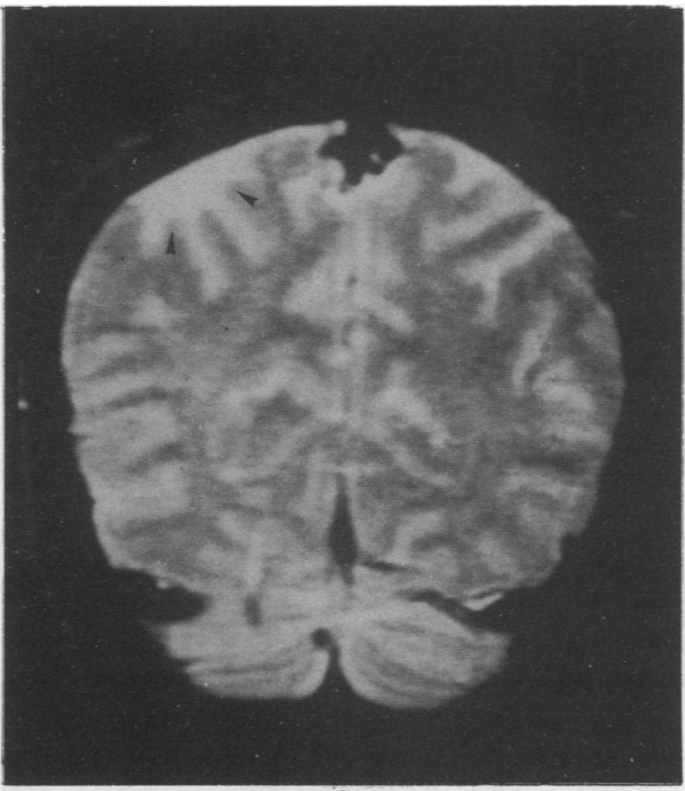

(b)

Fig. 4 Old cerebral infarction with focal atrophy. (a) This magnetic resonance spin echo image $(T R=2000 \mathrm{~ms} / T E=20 \mathrm{~ms})$ of patient 2 shows an area of focal cortical atrophy (arrowheads). (b) This spin echo image (TR=2000 ms/TE $=80 \mathrm{~ms}$ ) shows a right parietal area of high intensity corresponding to the area of focal atrophy in Fig. $4 a$ (arrowheads). These lesions did not change with sequential imaging and are consistent with an old area of infarction not related to the current episode of acute lupus cerebritis.

TE $=20 \mathrm{~ms}$ ) image which shows an area of focal atrophy. Figure $4 \mathrm{~b}$ (patient 2 ) is a $\mathrm{T} 2$ weighted image of the same area, which shows a fixed right parietal high intensity lesion representing infarct. Similar high intensity irreversible lesions were observed in the cerebellum.

Cerebral infarction in acute neuropsychiatric SLE was common but usually involved only small areas of the brain and did not usually result in a clinically recognisable focal neurological deficit. On the other hand, an accumulation of such lesions might be expected to result in a gradual decline of intellectual and motor function as the duration of the disease increases.

\section{MR FINDINGS OF DIFFUSE ATROPHY}

Cerebral atrophy was a common MR finding in patients with SLE (Figs 3 and 4) but was not associated with a particular clinical presentation. Generalised atrophy occurred more often in those patients with disease for five years or more $(6 / 8)$, and was present in only one patient with SLE of less than five years' duration. The presence of atrophy shown by MR did not influence subsequent treatment.

MR FINDINGS OF ACUTE INTRACEREBRAL H A E MORR H A G E

Figure 5 shows an acute intracerebral haemorrhage in a 10 year old patient with SLE (patient 7), who acutely developed a severe movement disorder. This high intensity lesion with a low intensity dark rim can be discriminated from the high intensity lesions of infarct and focal oedema. The haemorrhage involved the deep white matter structures and the basal ganglia, and correlated well with the clinical neurological findings.

SYMPTOMS AND MR FINDINGS

In this study headache was a completely non-specific complaint, which did not relate to a particular MR finding. Nineteen of 21 patients with SLE and CNS symptoms did complain of headache, however, and $15 / 19$ patients with headache had evidence of disease on MR scan. Thus headache should be viewed as a relatively sensitive, but non-specific indicator of CNS involvement in SLE. Acute organic brain syndrome was present in many patients with diffuse encephalopathy (8/19), though more subtle degrees of disordered cognitive function in the rest of the patients might have been shown if formal psychometric testing had been undertaken. Discrete neurological abnormalities, including movement disorder, paresis, and visual changes occurred with a variety of CNS lesions (see Tables 2 and 3). Seizures were observed only in patients with encephalopathy (5/ 


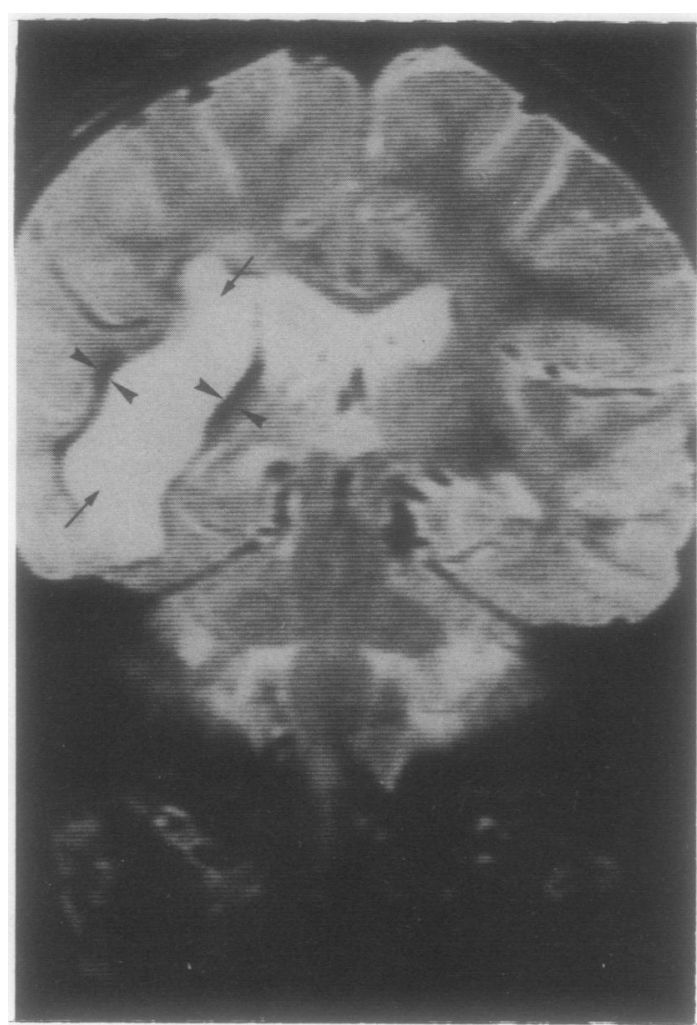

Fig. 5 Intracerebral haemorrhage. This $T 2$ weighted spin echo image $(T R=2000 \mathrm{~ms} / T E=80 \mathrm{~ms})$ of patient 7 shows a large haemorrhage within the right parietal and temporal white matter. The bright (high intensity) lesion (arrows) surrounded by a low intensity dark rim (arrowheads) indicates that the haemorrhage is subacute to chronic. This haemorrhage involved the basal ganglia, resulting in a movement disorder.

21), though presumably seizures could occur with other CNS complications of SLE, especially cerebral infarction, brain abscess, intracranial haemorrhage, and vasculitis.

\section{Discussion}

This study has shown the diagnostic value of MR in the evaluation of patients with SLE and acute neuropsychiatric disease. Magnetic resonance detected a diversity of lesions characterised by increased signal intensity on $\mathrm{T} 2$ weighted images that were not present on CT cranial images (Tables 2,3 , and 4). Diffuse encephalopathy in particular was characterised by reversible focal and punctate high intensity lesions in the white or gray matter, or both. These lesions resolved during the course of treatment and did not evolve into infarcts.

As MR detects the response of hydrogen nuclei to radiofrequency pulses in a high magnetic field, 을. increased intensity on $\mathrm{T} 2$ weighted MR images, es- $\Rightarrow$ pecially in the labile lesions, probably reflects $\stackrel{?}{?}$ increased water content of that tissue. ${ }^{6}$ This may not? be true of high intensity lesions, which may represent an increase in mobile lipid. The reversible $\frac{\bar{s}}{\sim}$ lesions associated with diffuse encephalopathy probably reflect increased water content of the affected tissue resulting from focal oedema associ- ated with ischaemia or increased vascular permeability.

The high intensity lesions evident on MR images may correspond to the sulcal enlargement present on certain CT images described by Gonzalez-Scarano et al, ${ }^{2}$ but MR is more sensitive and shows discrete lesions rather than the vague, gross structu ral enlargement present on CT images. These results $\vec{O}$ indicate that labile high intensity brain lesions evi- $\vec{A}$ dent on MR are associated with reversible neurolo-o gical abnormalities in many patients with SLE and may be a reflection of a diffuse CNS process.

The presence of reversible, oedematous lesions is consistent with the well reported paucity of histo-3 pathological lesions associated with CNS lupus. ${ }^{7} 80$ Indeed, the absence of significant disease in most necropsy studies suggests that the reversible highto intensity lesions do not represent infarct or necros. Reversible oedema of brain could be induced 取 acute changes in the blood brain barrier secondarys to vasculopathy, which would reverse when the barrier defect improved with or without treatment Likewise, patchy ischaemia could also result in such $\mathbb{2}$ regional and diffuse abnormalities. ${ }^{910}$

Antineuronal antibodies have been associate $\vec{\rho}$ with active lupus encephalopathy. ${ }^{11-13}$ The presences of such antibodies would be consistent with the $a b$ च sence of extensive infarction, the diffuse nature of the process, and the presence of reversible oedema of neural tissue. ${ }^{14}$ Although histological confirma tion of the labile and fixed, high intensity brain lesions apparent on MR is desirable, prior necrops $\subseteq$ studies in patients with SLE suggest that pathologi 2 cal confirmation may be difficult or impossible because of the absence of histologically demons- $\rightarrow$ trable lesions in most patients, especially those with을 diffuse encephalopathy. ${ }^{78}$

The role of corticosteroids in the resolution of labile, high signal intensity lesions is unclear, though our patients received high doses of these drugs. Cer tainly, further studies would be necessary to deter-O mine whether corticosteroids are responsible for theo reversibility of high intensity lesions. These studies may be difficult, however, because most clinicians? would not withold corticosteroid treatment if the patient were suffering from generalised seizures or ${ }^{\circ}$ psychosis. Indeed, the general trend in treatment of 
active SLE is towards aggressive corticosteroid and cytotoxic drug treatment. ${ }^{15}$

The findings of both reversible and fixed lesions in the same patients suggest the desirability of baseline MR studies in patients at risk for neuropsychiatric complications of SLE in order to differentiate new from old abnormalities. In addition, a cranial MR study is more valuable if obtained within 24 hours of the initial neurological event as the reversible, high intensity lesions associated with diffuse encephalopathy may resolve rapidly during the ensuing days with or without corticosteroid treatment. If new abnormalities are present, sequential images at 48 hours and one week may confirm the reversibility of the lesions. New lesions that persist imply evolving infarction and, if the patient's clinical condition supports this interpretation, may precipitate more aggressive treatment, perhaps with cytotoxic drugs or high dose corticosteroids.

In previous series MR was found to be more sensitive than CT scanning in the evaluation of patients with SLE. ${ }^{16-19}$ Our study shows that MR imaging is useful for the differentiation of other confounding CNS disorders affecting patients with SLE, such as intracranial haemorrhage, sinusitis, cerebellar lesions, and brain stem lesions. The white and gray matter lesions in this study seemed to be generally more extensive than those reported previously, ${ }^{16} 17$ but our findings may be related to the timing of the MR scans, which were obtained earlier (within 24 hours of admission), before corticosteroid treatment had been started. Because of this, more active, labile lesions might have been present on the initial studies.

The neurological complications of SLE affect a large proportion of patients. ${ }^{1}$ Cranial neuropathy, ${ }^{26}{ }_{21}$ peripheral neuropathy, ${ }^{22}{ }_{23}$ stroke, ${ }^{24-28}$ seizure, ${ }^{7}$ organic brain syndrome, ${ }^{1}{ }^{8}$ and movement disorder $^{29}$ are the most common, though affective disorders can also represent neurological involvement. ${ }^{30}$ Lesions similar to multiple sclerosis have also been reported. ${ }^{31-33}$ Generalised cerebral atrophy is a common finding of unclear significance ${ }^{24-36}$ and was also present in many of our patients.

Other imaging methods have been of limited use in the evaluation of neuropsychiatric lupus. ${ }^{1}$ Although radionuclide scanning was initially considered to be quite sensitive for lupus encephalopathy, ${ }^{37} 38$ more recent experience has shown that the method is insensitive and lacks specificity. ${ }^{1} 3439$ ${ }^{15} \mathrm{O}_{2}-\mathrm{C}^{15} \mathrm{O}_{2}$ scanning is very sensitive, but the oxygen nuclides are unstable and are only available in certain research centres. ${ }^{9}$ Positron emission tomography scanning with a number of different isotopes may provide valuable metabolic informa- tion but may be quite non-specific. ${ }^{40}$ Recently, xenon-133 has been used to determine cerebral blood flow in patients with SLE and appears to be a sensitive indicator of active CNS disease. ${ }^{10}$ The use of cerebral blood flow determinations, techniques which measure brain metabolism, and MR to define soft tissue anatomy and mobile proton content may provide the best combination of structural and physiologic data in the evaluation of patients with SLE and CNS complaints.

Computed tomographic scanning in acute lupus has been used to detect the presence of infarct, haemorrhage, abscess, and atrophy, but is insensitive. ${ }^{2616344142}$ Although $C T$ has shown the presence of generalised brain oedema, this diagnosis is somewhat subjective and is associated with poor specificity. ${ }^{6} 16$ In our series of patients with SLE focal and punctate oedema present on MR images was undetectable by CT scanning, even with enhancement. Computed tomography supplied diagnostically useful positive information in only $2 / 21$ patients and even in these patients CT was not superior to MR. The insensitivity of CT to small or discrete lesions might have been in part related to the greater slice thickness of the CT scans $(10 \mathrm{~mm})$ relative to that of MR $(5 \mathrm{~mm})$. Even when slice thickness is considered, however, the large lesions present on MR were not evident on CT, indicating that major differences in sensitivity existed between the two techniques.

In contrast, MR provided useful positive information in 15/21 patients. Thus cranial MR appears preferable for the routine evaluation of acute neuropsychiatric disease in patients with SLE. Six patients in our series, however, suffered from CNS symptoms consistent with mild encephalopathy without overt seizures or psychosis, yet the MR studies were competely normal (Table 4). Cranial MR, although more sensitive than CT, may be too insensitive to detect lesions in patients with SLE and only mild CNS involvement. Alternatively, mild CNS involvement in SLE may be purely physiological with no changes in anatomical structure or mobile proton content and might therefore be expected to be invisible to both $C T$ and $M R$.

In conclusion, MR has particular value in the patient with SLE with acute neuropsychiatric complaints. Magnetic resonance detects reversible focal lesions, infarct, atrophy, intracranial haemorrhage, and other CNS lesions that occur commonly in patients with SLE (Table 4). In contrast, CT has a low diagnostic yield (less than $10 \%$ ) in neuropsychiatric SLE. In some patients sequential MR scans may be useful objectively for following the therapeutic response of reversible high proton intensity CNS lesions. We conclude that for the evalua- 
tion of acute neuropsychiatric SLE MR is useful and provides more information than cranial CT.

This work was supported in part by the Lupus Foundation of America-New Mexico Chapter, the Flinn Foundation, and a grant to the Center for Non-invasive Diagnosis from the State of New Mexico.

\section{References}

I Bluestein H G. Neuropsychiatric disorders in systemic lupus erythematosus. In: Lahita R G. cd. Sistemic lupus erythematesus. New York: Wiley 1987: 593-614.

2 Gonzalez-Scarano F. Lisak R P. Bilaniuk L T. Zimmerman R A. Atkins P C. Zweiman B. Cranial computed tomography in the diagnosis of systemic lupus erythematosus. Ann Neurol 1979: 5: 158-65.

3 Grigor R. Edmonds J. Lekonia R. Bresnihan B. Hughes G R. Systemic lupus crythematosus. A prospective analysis. Ann Rheum Dis 1978: 37: 121-8.

4 Feinglass E J, Arnett F C. Dorsch C A. Zizic M. Stevens M B. Neuropsychiatric manifestations of systemic lupus erythematosus: diagnosis, clinical spectrum, and relationship to other features of the disease. Medicine (Baltimore) 1976; 55: 323-39.

5 Tan E M. Cohen A S. Fries J F. et al. 1982 Revised criteria for the classification of systemic lupus erythematosus. Arthritis Rheum 1982; 25: 1271-7.

6 Brant-Zsawadzki M. Mills C M, Norna D. Central nervous system, In: Margulis A R, Higgins C B, Kaufman L, eds. Clinical magnetic resonance imaging. San Francisco: Radiology research and education foundation. 1983: 91.

7 Johnson R T. Richardson E P. The neurological manifestations of systemic lupus erythematosus. A clinical-pathological study of 24 cases and review of the literature. Medicine (Baltimore) 1968; 47: 337-69.

8 Ellis S G. Verity M A. Central nervous system involvement in systemic lupus erythematosus: a review of neuropathological findings in 57 cases. 1955-1977. Semin Arthritis Rheum 1979: 8: 212-21.

9 Pinching A J, Travers R L. Hughes G R. Jones T. Moss S. Oxygen-15 brain scanning for detection of cerebral involvement in systemic lupus erythematosus. Lancet 1978; i: 898-900.

10 Kushner M J. Chawluk J, Fazekas F. et al. Cerebral blood flow in systemic lupus erythematosus with or without cerebral complications. Neurology 1987: 37: 1596-8.

11 Wilson H A. Winfield J B. Lahita R G. Koffler D. Association of IgG antibrain antibodies with central nervous systemic dysfunction in systemic lupus erythematosus. Arthritis Rheum 1979; 22: 458-62.

12 Bluestein H G. Williams G W. Steinherg A D. Cerebrospinai fluid antibodies to neuronal cells: association with neuropsychiatric manifestations of systemic lupus ervthematosus. Am J Med 1981: 70: 240-6

13 Robbins M L. Kornguth S E. Bell C L, et al. Antineurofilament antibody evaluation in neuropsychiatric systemic lupus erythematosus: combination with anticardiolipin antibody assay and magnetic resonance imaging. Arthritis Rheum 1988; 31: 623-41.

14 Bluestein H G. Neuropsychiatric manifestations of systemic lupus erythematosus. $N$ Engl J Med 1987; 317: 309-11.

15 Austin H A III, Klippel J H, Balow J E. et al. Therapy of lupus nephritis: controlled trial of prednisone and cytotoxic drugs. $N$ Engl J Med 1986; 314: 614-9.

16 Vermess M. Bernstein R M. Bydder G M. Steiner R E. Young I R, Hughes $G$ R. Nuclear magnetic resonance (NMR) imaging in systemic lupus erythematosus. J Comput Assist Tomogr 1983: 7: 461-7.

17 Aisen A M. Gabrielsen T O. McCune W J. MR imaging of sys. temic lupus erythematosus involving the brain. $A J R$ 1985: 144: 1027-31.

18 McCune W J. Golbus J. Neuropsychiatric lupus. Rheumatic Diseases Clinics of North America 1988; 14: 149-67.

19 McCune W J. MacGuire A. Aisen A. Gcbarski S. Identification of brain lesions in neuropsychiatric systemic lupus erythematosus by magnetic resonance scanning. Arthritis Rheum 1988: 31: $159-66$.

20 Meyer M W. Wild J W. Unilateral internuclear ophthalmoplegia in systemic lupus erythematosus. Arch Neurol 1975: 32: 음 486-9.

21 Ashworth B. Tait G B W. Trigeminal neuropathy in connective $\bar{S}$ tissue disease. Neurology 1971: 21: 6(1)9-14.

22 Bailey A A. Sayre G P. Clark E C. Neuritis associated with sys- $\varrho$ temic lupus erythematosus: report of five cases with necropsy in two. AMA Archives of Neurology and Psychiatry 1956: 75: 2519.

23 Lewis D C. Systemic lupus and polyncuropathy. Arch Intern Med 1965: 116: $518-22$

24 Silverstein A. Cerebrovascular accidents as the initial manifestations of lupus erythematosus. NY State J Med 1963: 63: 29428.

25 Trevor R P. Sondheimer F K. Fessel W J. Wolpert S M. $\frac{\vec{\infty}}{\infty}$ Angiographic demonstration of major cerebral vessel occlusion in systemic lupus erythematosus. Neuroradiology 1972: 4: 2112- N 7.

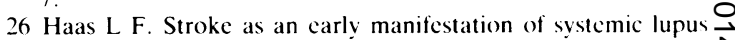
erythematosus. J Neurol Neurosurg Psychiatry 1982: 45: 5.54-6. $\$$

27 Casey E B. Symon L. Systemic lupus erythematosus presenting 윽 as subarachnoid hacmorrhage and space occupving lesion. $\mathrm{BrJ} \longrightarrow$ Dermatol 1971: 84: 157-60)

28 Kelley R E. Stokes N. Reves P. Harik S I. Cerchral transmural angiitis and ruptured ancurysm: a complication of systemic $\varnothing$ lupus erythematosus. Arch Neurol 1980: 37: 526-7.

29 Lusins J O. Szilagyi P A. Clinical features of chorea associated with systemic lupus erythematosus. Am J Med 1975: 58: 857-(⿻力.

30 Bennahum D A. Messner R P. Recent observations on cenfigi nervous system lupus ervthematosus. Semin Arthritis Rhe 1975: 4: 253-66.

31 Mizutani T. Oda M. Tsuganezawa M. et al. A case of demve nating encephalomyelitis with some resemblance to colligen disease. J Neurol 1977: 217: 4.3-52.

32 April R S. Vansonnenberg E. A case of neuromvelitis optica (Devic's syndrome) in systemic lupus erythematosus. Neurolog! 1976: 26: 1066-70.

33 Kinney E L. Berdoff R L. Rao N S. Fox L M. Devic s sundrome and svstemic lupus ervthematosus: a case report with necropsy. Arch Neurol 1979: 36: 643-4.

34 Carette S. Urowitz M B. Grossman H. St Louis E L.. Cranial J computerized tomography in svstemic lupus ervthematosus. Rheumatol 1982: 9: 855-9.

35 Bentson J. Reza M. Winter J. Wilson G. Steroids and apparent cerebral atrophy on computed tomography scans. J Comput Assist Tomogr 1978: 2: 16-23.

36 Adelman D C. Saltiel E. Klinenberg J R. The neuropsychiatrie manifestations of systemic lupus erythematosus: an overvicu. Semin Arthritis Rheum 1986: 15: 185-99.

37 Bennahum D A. Messner R P. Shoop J D. Brain scan findings in central nervous system involvement by lupus erythematosus. Ann Intern Med 1974: 81: 763-5.

38 Tan R F. Gladman D D. Urowitz M B. Milne N. Brain scano diagnosis of central nervous system involvement in svstemic lupus erythematosus. Ann Rheum Dis 1978: 37: 357-62. N

39 Norman A. Shapecro L G. Lee S. The radiology of systemie lupus erythematosus. In: Lahita R G. ed. Sistemic lupus erythe - O matosus. New York: Wilev. 1987: 421-95.

40 Hiraiwa M. Noualen L. Abe T. et al. Positron emission tomo- $-\omega$ graphy in systemic lupus erythematosus: relation of ecrebralo vasculitis to PET findings. American Journal of Neuroradioe $\log y$ 1983; 4: $541-3$

41 Bilaniuk L T. Patell S. Zimmerman R A. Central nervous system disease in systemic lupus erythematosus. Radiology 1977: 124: 119-21.

42 Gaylis N B. Altman R D. Ostrov S. Quencer R. The selectivi value of computed tomography of the brain in cerebritis due to systemic lupus erythematosus. J Rheumatol 1982: 9: $85(1-4$. 